\title{
EL FRACASO DEL MUTUO ENTENDIMIENTO Y DE LA REVOLUCIÓN EN SIETE RELATOS SOBRE EL AMOR Y LA GUERRA ${ }^{1}$
}

\author{
Jorge Chen Sham
}

\begin{abstract}
RESUMEN
La ruptura espacio-temporal y diegética existente entre las dos partes de la novela Siete relatos sobre el amor y la guerra (1986) obliga a tomar en consideración que su Segunda Parte, "Sobre la guerra", narra acontecimientos anteriores a la Primera Parte, "Sobre el amor". La novela aparece estructurada en forma de un díptico; se trata de un gran retablo en dos cuadros que hace un balance de los alcances de la revolución sandinista. Las historias de mujeres que nos presenta esta novela no tienen un desenlace completamente eufórico; plantean el desfase entre el proyecto de construcción nacional y las dificultades para realizarse en un mundo machista. He ahí el gran fracaso que Rosario Aguilar quiere testimoniar en Siete relatos; ello no se logra automáticamente con tomar las mismas armas codo a codo con los hombres, ni asumir juntos la reconstrucción del país. La revolución por hacer está en el plano de los afectos y de la comprensión de las diferencias biológicas y de género.

Palabras clave: Rosario Aguilar, novela nicaragüense, revolución sandinista, Siete relatos sobre el amor y la guerra.
\end{abstract}

\begin{abstract}
The space-time rupture and "diegética" that exists in the two parts of the novel "Seven Tales of Love and War" (1986) obliges us to take into consideration that the second part, "About War" narrates events that occurred before the events in the frist part, "About Love". The novel appears to be structured in the form of a diptych, a series of paintings on two tablets, and is treated as an epic story that puts into equilibrium the two extremes of the Sandinista revolution. The stories of the women that are presented in the novel do not have a completely euphoric unraveling; which sets the stage for the conflict between the national reconstruction projects and the difficulties in accomplishing them in a male chauvinistic world. Behold there the great disaster that Rosario Aguilar wants to testify to in "seven Tales"; it is not automatically accomplished by taking up the same weapons, shoulder to shoulder, with the men, nor assuming together responsibility for the reconstruction of the country. The revolution must take into account in its plans, the feelings and understanding of biological and gender-based differences.
\end{abstract}

Dr. Jorge Chen Sham. Profesor de la Escuela de Filología, Lingüística y Literatura, Universidad de Costa Rica. San Pedro, San José, Costa Rica.

Correo electronico: jorgec@le.ucr.ac.cr

Recepción: 18-04-05

Aceptación: 19-04-05 
Rosario Aguilar publica en 1986 sus Siete relatos sobre el amor y la guerra en un momento en el que la revolución sandinista se había aquilatado y había mostrado, al mundo y a los nicaragüenses, sus logros y fracasos, por lo que, al referirse tanto a la etapa de sublevación e insurrección final contra el dictador Anastasio Somoza, así como a la posterior implantación del FSLN en el poder, la novela de Aguilar nos ofrece un balance del proyecto de la revolución sandinista. Muy acertadamente observó Nydia Palacios, en su fundamental libro Voces femeninas en la narrativa de Rosario Aguilar, que esta novela continúa el tema de la revolución comenzado en 1976 con El guerrillero, en la que los "personajes femeninos son conscientes del papel protagónico en la construcción del gran proyecto nacional acorde con los cambios sociales que se están dando en América Latina en esos años" (182-3).

Las protagonistas de Siete relatos no son ajenas al vaivén político que vive Nicaragua en los últimos años de la década de los 70; es más, toman partido y todas ellas se unen a la revolución en marcha, salvo una de ellas, María Elena ${ }^{2}$. Con ello, Aguilar pone a las mujeres en esa toma de conciencia que significa abrirse al espacio exterior, dejar sus familias y sus hogares, para militar en la esfera pública y construir los destinos de la nación. Hasta aquí, todo parece indicar una interpretación positiva y exultante del papel de las mujeres en Siete relatos; pero hay algo que llama la atención en cuanto a la estructura y a la organización del texto que merece nuestra atención, además de un común denominador que encontramos en las siete historias de mujeres que narra la novela. Veamos.

Señalaba ya Nydia Palacios la ruptura espacio-temporal y diegética que existe entre las dos partes de la novela (188). La Segunda Parte de Siete relatos 3 , "Sobre la guerra", trae el subtítulo "Adiós para siempre" y narra acontecimientos anteriores a la Primera Parte, "Sobre el amor”. Se dedica a contarnos las historias de María José, Lucía, Sonia y Karla, cuatro mujeres que se deciden por la guerrilla presentándonos el mundo de la lucha armada, la resistencia popular y la respuesta del régimen dictatorial a la sublevación.

La novela aparece estructurada en forma de un díptico; se trata de un gran retablo en dos cuadros que hace un balance de los alcances de la revolución sandinista. Desde el punto de vista estructural, la ruptura entre las dos partes de la novela es llamativa y si está ahí, posee un sentido. No está contada la historia de forma cronológica dentro de una organización ordenada de la diégesis en lo que se refiere a causa y a efecto, pues la movilización de la guerrilla hacia la insurreción final es anterior al triunfo del sandinismo y a la posterior instauración del Régimen de izquierdas (Salamanca). La ruptura está ahí para que comprendamos el vacío existente entre las grandes expectativas y los proyectos que generó la Revolución Sandinista y su posterior implantación en el plano de las relaciones humanas. Dicho de otra manera, la ruptura debe comprenderse como la puesta en evidencia del proyecto humanista y de reivindicación de los derechos humanos que significó el nuevo régimen y su acción concreta en la esfera de las relaciones entre hombres y mujeres. A eso me refiero cuando hablo de fracaso del mutuo entendimiento y de los ideales que la Revolución pregonaba en materia de equidad de género y de comprensión entre los sexos. En 1991, Daisy Zamora hace un balance de sus alcances de la siguiente manera 4 :

La obra no está concluida, pero las mujeres de Nicaragua hemos vislumbrado nuestra humanidad, hemos vislumbrado nuestro futuro a través de propios y accidentados y sorprendentes caminos. Todas las mujeres tienen que buscar los suyos propios (958). 
Magistralmente, Rosario Aguilar lo intenta ya muy tempranamente, en 1986, en pleno régimen sandinista. Siete relatos nos introduce en el espacio de las luchas políticosociales y en la búsqueda de realización amorosa en el espacio privado. La pregunta obligada es si ambos espacios son compatibles, si pueden conjugarse en la esfera de un entendimiento entre los dos sexos.

Corresponde la novela de Aguilar a la primera etapa de la interpretación de los movimientos guerrilleros por parte de la literatura latinoamericana, que he esbozado en otro lugar (Chen 2003). La organización de la guerrilla con su cuestionamiento de la reali$\operatorname{dad}^{5}$ desemboca en la movilización de la sociedad civil, por medio de la decisión valerosa y consciente de muchos de sus actores de ingresar en el movimiento sandinista. Se trata de observar la concientización en sectores populares que ingresan a formar parte de los grupos que, bajo el ideario del general Sandino, se aglutinan con el proyecto de liberar a Nicaragua de la dictadura somocista. y del imperialismo yanqui.

Las aspiraciones de cambio del Frente Sandinista de Liberación Nacional deben interpretarse dentro de la lógica de los movimientos revolucionarios populares que aparecen en América Latina a partir de la revolución cubana; su objetivo es "la incorporación de todos los sectores populares a la lucha liberadora" (Rubio Cordón 1983: 355), aunque también involucró a clases medias e intelectuales, con un apoyo abierto y franco de todos ellos, excepto de la oligarquía nicaragüense. Es aquí en donde debemos situar la participación de las mujeres aguilarianas en la lucha revolucionaria: ellas responden a la toma de conciencia que significa enrolarse en la guerrilla, lo cual significa estar codo a codo y mano con mano a la par de los hombres.

De manera que si el proyecto de FSLN era incorporar a todos en la movilización, que fuera de todos los sectores sociales y genéricos, las historias de mujeres que nos narra Siete relatos no hablan de esa igualdad que resulta de combatir al mismo enemigo, ni tomar las mismas armas, ni recorrer los mismos caminos. Está bien que se busque el apoyo y la solidaridad de las mujeres; pero ello no significa que el entendimiento y la igualdad se logren automáticamente. Ello es patente en el divorcio o la separación que se establecerá entre el espacio público y el privado, cuando se tome en cuenta la realidad de las diferencias biológicas y de género; esto es evidente en todas las historias que conforman Siete relatos, salvo en el caso de María Elena.

Ahora bien, para efectos de nuestro análisis, como la novela se presenta como un díptico, hemos seleccionado en cada parte de la novela dos historias a manera de retratos femeninos. El primer caso es el María José; ella debe enfrentarse sola a la experiencia de la maternidad:

\footnotetext{
Siente un gran desamparo. Miedo de la noche. Miedo de regresar a la ciudad, a la clandestinidad. La inmensa soledad que experimenta al reconocer que tiene que enfrentarse completamente sola, a la terrible y desconocida experiencia de tener ipor primera vez! Un hijo. ¡Y en qué adversas circunstancias! Sin compañero para compartir la responsabilidad. Sin madre que la acompañe y asista (113).
}

La incertidumbre se apodera de María José; el sentimiento de desamparo es concomitante a la carencialidad de las relaciones humanas que se expone en esta historia6; de ahí que subraye el texto tanto la ausencia del compañero, es decir, su pareja, y, aún más crítico, la ausencia de la madre. Los sentimientos que embargan a María José están dominados por esa tremenda soledad, la cual es el precio que ha debido pagar por querer romper con el pasado y renunciar a su familia. Ahora, tiene que dejar el campamento de las montañas porque es inmi- 
nente la insurrección final; por ello, tampoco es útil a la causa por su estado de preñez y no puede regresar más a las montañas. En esa confusión de sentimientos contradictorios, María José realiza una equiparación ideológica que no es nada inocente. No solo su destino no tiene marcha atrás, tampoco la revolución que tomará las ciudades; su embarazo, como el ataque final, están a punto de suceder:

\footnotetext{
A pesar de tantos factores que se oponen, la ofensiva final para junio de 79, es ya un hecho. Un proceso irreversible. Nadie puede detenerla. Ha entrado en su fase final, al conteo regresivo. Como su embarazo. Nadie, tampoco, puede detenerlo, impedirlo. Ha comenzado su última etapa, y como un hecho natural, inevitable, tiene que llegar a su término (113-4).
}

Contigüidad obliga, la asociación entre el fruto de su embarazo, el hijo por nacer y el producto de la ofensiva final, la caída del dictador, entran en una connivencia contradictoria. Ambos son actos irreversibles. El primero nunca lo quiso, fue su desliz y ahora debe pagar el precio del ostracismo y de la separación; el segundo, la anhelada “ofensiva final", por la cual ha luchado ostensiblemente, se hará sin su participación. La maternidad es un estorbo y un error pero no hay marcha atrás. Ello explica los sentimientos de amor / odio que expresa María José hacia la criatura que lleva en su vientre. Siente coraje y rabia de no poder ser testigo activo de lo que empezará en lo inmediato:

\footnotetext{
Así de simple. Ella bajando de la montaña para poder parir. Y todos saben que en las ciudades y en los pueblos y los campos, de un momento a otro, estallará la guerra. Bajando de la montaña para poder parir [...] (115).
}

La incompatibilidad entre la maternidad y la guerra es evidente en todo el texto. Apoyándose en una mirada retrospectiva, a raíz del cuero reluciente del automóvil de lujo que transporta a María José, el narrador omnisciente repasa la vida anterior de la futura madre para justificar su ofuscación presente. Los recuerdos la invaden y la narración adopta la forma de un relato de vida que muestra la conversión guerrillera de María José, hija de buena familia, ahora viviendo en la clandestinidad de la guerrilla. Ello implica tomar una decisión responsable y cortar los lazos familiares, lo que, ahora, en la vivencia de esta experiencia límite, justifica su vacilación y el recuerdo de la madre la inunda como posibilidad de un regressus ad uterum, en donde pueda hallar la paz y la tranquilidad necesaria para dar a luz sin las molestias y el desamparo de los suyos en este momento crucial:

\footnotetext{
Desea de manera primitiva un lugar seguro y acogedor donde esconderse y parir. En paz, como cualquier hembra, del reino animal. Sin fuga. sin persecución (118).
}

Pero como ha cortado los lazos con su familia, como es una guerrillera y puede ser que la busquen los guardias somocistas, no puede regresar. La confusión y los recuerdos se suceden en su mente; de nuevo la respuesta de su cuerpo a la maternidad avanzada crea una atmósfera necesaria a la intriga y al desarrollo posterior de los acontecimientos. El malestar que siente María José a raíz de ese sentimiento de abandono y de indefensión total prepara al lector, en el plano de lo intuitivo, para que juzgue que algo extraño o insólito está por suceder. Rosario Aguilar saca provecho de lo somático y el transtorno anímico que experimenta María José se reproduce en su cuerpo: 
Por fuera... porque se siente aterrorizada ante la inminencia de su parto clandestino. Primeriza. Escondida. Sin nada listo. Si[n] $]^{7}$ saber si el corazón casi se le detiene, débil, disparejo, por falta de aire dentro de sus pulmones comprimidos, o por los ruidos desconocidos que vienen del exterior, de la carretera, de los pueblos por los que pasan a cien kilómetros por hora, de la obscuridad, de la noche (118).

Aunque, como indica el narrador, su respiración irregular y la taquicardia pueden deberse a su embarazo, María José no solo ha somatizado la angustia y la soledad de su actual situación, sino que también responde a ese miedo y al horror de imaginar las atrocidades de la guerra y a los vejámenes de la dictadura. Una imagen es aquí redundante; "puede ser sinónimo de muerte" (118), dice ella, ese ruido ensordecedor que inunda las calles de Nicaragua, pero la oscuridad de la noche es síntoma de algo más, de un futuro incierto que se traduce más adelante en el texto, con ese miedo de morir en cualquier retén del camino o, en el peor de los casos, morir ella misma: “Tiene miedo. Miedo por primera vez en cuatro años. Miedo de morir, miedo a parir entre desconocidos" (121).

Además, el leitmotiv recurrente de la soledad toma un nuevo giro cuando María José recuerda su entrenamiento en la guerrilla, la vida clandestina y perentoria que llevaba y, sobre todo, la necesidad de guardarse los sentimientos y reprimir los afectos. No es inocente la correlación entre la vida de los campos guerrilleros y la carencialidad afectiva. Aquí la historia de María José se agrieta para mostrarnos su lado humano: "Sin embargo un guerrillero necesita también momentos de ternura. Por muy fuerte y duro que sea, o que se crea" (119). Los encuentros furtivos con uno de sus camaradas, oficial de rango superior, terminan por despertar el lado romántico de la relación de pareja; la naturaleza que acompaña a los amantes y la retórica de la aurora se convierten en los tópicos para expresar las ilusiones de enamorada que posee María José; pero la realidad vuelve a su curso con la cruda constatación de que no hay marcha atrás ni para la revolución en marcha ni para mostrar afectos en tiempos bélicos, cuando le ordenan que abandone el campamento y se dirija a la ciudad para parir. Es cuando ella se da cuenta de que, en realidad, no ha habido de parte de su compañero verdadero afecto y que en cualquier momento el hombre de su vida, el padre de su hijo, puede morir:

\footnotetext{
La relación terminó con el adiós. Los vínculos se rompieron. La seguridad de los dos. adiós para siempre. Tenía que ser así.

Y no debía de dolerse. Su corazón ya debería de haberse endurecido con tantos años... de saber que un amor en la montaña puede desbaratarse en menos del instante que tarda un disparo (122).
}

No solo se trata de la posibilidad de que su compañero muera, sino también de lo efímero de la relación amorosa que los une y de que la muerte la encuentre a la vuelta de la próxima esquina. En este momento en el que ella misma se conmina a no ablandarse, surge el sentimiento de frustración asociado a su ascenso en el mando de la guerrilla y los problemas que tuvo para demostrar a los compañeros de lucha "su vocación guerrillera" (122). Ello no es de ninguna manera inocente. El embarazo aparece como un obstáculo que no le permitirá continuar en la guerrilla, ni participar en la insurrección definitiva; eso es lo obvio en el texto. Pero el embarazo la obliga a repensar su condición genérica y las diferencias biológicas, pues por más "causa revolucionaria" (122) a la que ha entregado alma y vida, se impone la realidad:

Incluso, había renunciado totalmente y por la causa, a todo afecto... pero ¡cómo desearía, por ahora, ser amada! (123) 
La conjunción adversativa "pero" resume excelentemente la contradicción de la que venimos hablando. Como guerrillera no puede mostrarse con sensiblerías, es decir, débil de carácter; sin embargo, su situación de desamparo y la experiencia límite que vive la conducen a buscar el afecto y anhelar la relación de pareja. Esto es radicalmente imposible e inaceptable en el código de la guerrilla, pues la aparta del ansiado triunfo y la excluye de ese mundo "masculino" que se ha forjado. Ahora bien, el desenlace de lo que le sucede a María José se posterga hasta el capítulo siguiente, dedicado a Karla, con la que estará indisolublemente ligado su destino.

Karla representa a la guerrillera que cumple funciones de enlace y de espía. Pinillos habla de dos tipos de estrategia de la guerrilla, dependiendo de si su radio de acción es el campo o la ciudad ${ }^{8}$. En la ciudad, en la primera fase de la estrategia revolucionaria, su objetivo es la espectacularidad, ser visibles e infundir la sensación de que el gobierno no controla la situación (178); en la segunda fase de la estrategia urbana, hay que dedicarse a buscar casas que sirvan de refugio para los guerrilleros, procurar suministros e información. Esto es lo que realiza Karla con miras de que se produzca el asalto final de la ciudad de León. Karla debe buscarle refugio temporal a María José, ocultarla en una casa-relevo en la que pueda dar a luz. Ella está muy preocupada por el estado en que recibe a la joven parturienta; la encuentra muy desmejorada y desaliñada, como si no aguantase más el embarazo, lo cual parece indicar que comenzará pronto las labores de parto. Aquí lo que llama la atención es la comparación que realiza el narrador entre el comentario de Karla, reproducido en forma de discurso directo, y sus apreciaciones sobre el asalto a la ciudad de León:

\footnotetext{
Y la ciudad cargada, más aún que la embarazada. Llevando sobre sus edificios, sobre sus habitantes, sobre cada una de sus calles, la inminente y dolorosa explosión de algo terrible. Del desenlace de la larga tragedia (126).
}

De nuevo, la contigüidad crea una atmósfera que anuncia el desenlace tanto de la guerra contra el dictador como de la historia personal de María José; la sangre derramada y la "inminente y terrible explosión" es también la placenta de la parturienta reventada, como veremos a continuación. Como las labores de parto comienzan, Karla busca una partera y prepara el alumbramiento hirviendo sábanas en las que envolverá al recién nacido. Mientras ella está en el lavadero, divisa a unas patrullas que se apuestan frente a su casa. Los han delatado y los guardias irrumpen a ritmo de ametralladoras; las ráfagas son estridentes. Cuando se marchan después de haber cumplido su misión, Karla entra temblorosa en la casa para descubrir el cuadro de horror; todos los ocupantes han muerto y su visión se va ocupando de cada uno hasta llegar a María José:

\footnotetext{
Pero lo peor no es eso. La María José. En el baño. Todavía viva. Da gritos desesperados y angustiosos. Desgarradores. [...] La María José con su vientre reventado como un mango maduro. "Gimiendo y llorando en este valle de lágrimas" Su dolor es intenso... porque no proviene tan sólo de su muerte, del desgarramiento físico de su cuerpo, sino y también, del dolor de parto...ya era la hora (128).
}

La escena es espeluznante; denuncia no solo la brutalidad de la represión, sino las atrocidades que cualquier conflicto bélico produce en los seres humanos. El espectáculo es de una gran crueldad para quien se presenta desde ahora como una víctima de la guerra. Pero no hay tiempo para llorar a los caídos por la causa, a Karla la han delatado y debe huir para ocultarse en la primera casa en la que la dejan entrar. Unos momentos de respiro y los 
pensamientos se suceden rápidamente en su mente a causa de "la masacre" (130) que acaba de presenciar, su respiración es errática y es cuando se da cuenta de lo que ha ocurrido; el choque emocional es tremendo: "Su voz enmudecida. Sus piernas sin vigor. Se siente mareada. Quisiera vomitar. Quisiera llorar eternamente" (131). Ante el dolor que experimenta, debe actuar con entereza; el protocolo de la guerrilla la obliga a escapar, seguir las instrucciones, de ello depende la supervivencia. Para lograrlo se obliga a sí misma a pensar en sus seres queridos, el hijo y la madre que la esperan:

Motivara su cerebro para que funcione. A ver si se acordaba de cuando daba sus clases allá en su pueblo. De la cara de su mamita. Del rostro de su hijito. El color de sus ojos. Su voz. Su voz llamándola: "mamita" (131).

El mayor aliciente para continuar con vida es su familia; al fin y al cabo lo que vale en la existencia son los afectos humanos; ello neutraliza las imágenes de muerte y la violencia que la guerra engendra. La historia de Karla continúa en el capítulo final de la novela, cuando descubramos justo en la última línea del texto la verdadera identidad de Karla; ella es "Margarita Madariaga. Maestra rural" (154) ${ }^{9}$. La recuperación del nombre tiene un significado positivo: quien se esconde bajo la identidad ficticia de "Karla", su nombre de guerrillera, recobra ahora su vida y anuncia su determinación de cerrar un capítulo de su biografía personal. Justamente este capítulo VI nos sitúa en el día del triunfo definitivo, el 20 de junio del 79, cuando los guerrilleros entran en Managua para celebrar el derrocamiento del régimen somocista. Acompañada de su hijo, ella es testigo activo del triunfo de la Revolución y partícipe como otros muchos nicaragüenses, con sus gritos, vítores y cánticos, de ese momento histórico en la historia reciente de Nicaragua. En la caravana de guerrilleros que marchan por las calles, atisba al padre de su hijo, el antiguo dirigente estudiantil que curó en el 75 (130) y de quien se había enamorado:

\footnotetext{
Ella quiere "señalarle su héroe al niño"... y de pronto, como sintiendo un destello, reconoce a sus amados ojos infinitos... que parecen al pasar, posarse en ella. [...]

Pero se posan sobre ella tan sólo por un instante. El suficiente para reconocerle. ¡Cómo no reconocerle! Cuando tantas y tantas noches ha pasado su descripción por su cerebro. De memoria. Repetidamente (152).
}

Ante la mirada pasiva e impávida del hombre de su vida, que no parece reconocerla, Margarita comprende la realidad de su relación; para él tal vez no significó nada esa entrega de su cuerpo y de la que nació un hijo; para ella representa todo, diferencia sustancial en el plano de los afectos. "Es tan sólo una ilusión" (153) como fenómeno óptico de una mirada fortuita, acota ella, con la resignación de quien descubre la triste verdad. Es más, el triunfo de la Revolución y la construcción del país se ven como una empresa que lo alejarán hasta separar sus caminos para siempre: "Va comprendiendo que la corriente del cambio lo llevará navegando sobre aguas y lo arrastrará a riberas que jamás lo acercarán a ella... así, así había sido antes" (153). Las esferas de acción los separan; él se dedicará a una empresa que, en el contexto, se ve como natural de lo masculino, "y, por ende, le corresponde gobernar" (Guerra 17) en esa lógica que aparta a las mujeres de espacio público, pues ella volverá a su trabajo de maestra rural. Hay un desfase. Margarita se enroló en la guerrilla, tomó las armas y luchó a la par de sus compañeros varones; eso le cuesta casi el pellejo y, sin embargo, ella no es participante activa del desfile del triunfo; es una simple espectadora. 
A eso me refería cuando hablaba, al principio, del fracaso del mutuo entendimiento y de los ideales que la Revolución pregonaba en materia de equidad de género y de comprensión entre los sexos.

Por eso, una vez que la Revolución triunfe y comience la reconstrucción del país, Siete relatos nos pone, en la pareja de hermanas Leticia y Paula, el ejemplo contundente de la incomunicación entre hombres y mujeres. Son el prototipo de las mujeres que, abrazando los ideales revolucionarios, se entregan a la causa. El caso de Leticia es paradigmático. En tanto maestra recién graduada, joven con grandes ilusiones de servir a la patria, siente la necesidad imperiosa de participar en la gran campaña de alfabetización nacional que lanza el Gobierno Sandinista a principios de los 80; una cruzada que se enmarca en el programa de reconstrucción que movió a las izquierdas del orbe y permitió la llegada de varios miles de internacionalistas. La novela pondera los proyectos juveniles, la ingenuidad y la pureza de espíritu en Leticia, comparándola con "la novia recatada y luminosa cuando sale de la iglesia y se despide" (18). Ello no es casual. Un mundo de esperanzas y de sueños se le abre a Leticia: el descubrimiento de la geografía del país y el orgullo de participación en la construcción nacional son elementos que marcan su historia y la caracterizan como un relato de aventuras. El viaje la conducirá al otro lado de Nicaragua, a la costa atlántica, tan diferente y exótica a sus ojos, en la que conoce a un misquito de nombre Cristy, del cual se enamora apasionadamente y deja todo por él ${ }^{10}$, a pesar de que la razón le dictase la opinión contraria: "aunque su mente le razonó que ella no podría habituarse al mundo de él, aunque los parientes y amigos trataron de detenerla. [...] Fue insensata y le siguió" (44). Del amor apasionado del principio de la relación pasamos a la decepción amorosa. Las palabras iniciales del capítulo II de la Primera Parte son reveladores de la transformación operada en Leticia y crea, estratégicamente, esa atmósfera que muy bien sabe sugerir Rosario Aguilar:

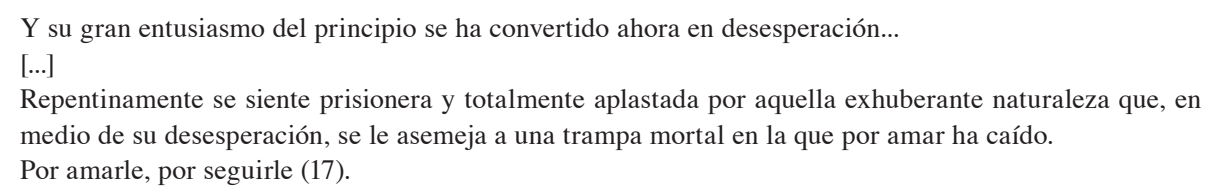

La desilusión, la soledad y el agobio la embargan. Más adelante nos enteramos de que Leticia está en la última etapa de su embarazo y que espera a que regrese Cristy en una noche que se hace larguísima y en la que pasa revista a su vida. Al igual que María José tiene miedo, miedo de dar a luz sola en esos parajes tan aislados de la civilización, en donde la naturaleza lo invade todo y representa también un peligro; de ahí el miedo que siente estando sola a punto de parir; está expuesta y se siente vulnerable: "Tiene miedo. Miedo a estar completamente sola y rodeada de aquella selva espesa y ya casi para cumplir los nueve meses de embarazo..." (39-40). Ello explicaría las razones por las cuales siente que la selva es su prisión. Sin embargo, anuncia algo más, el malestar y la crisis existencial por la que atraviesa Leticia y que se expone de forma indirecta aquí con su incapacidad para reconocer la geografía de los parajes en donde habita:

[...] es algo distinto, no lograría descifrar las vueltas del río ni los posibles senderos en las selvas. [...]

Los foráneos se extravían y navegan hacia otros ríos que no son los que precisamente buscan y que no se dirigen a ninguna salida, sino que se adentran hacia laguna más alejadas (20). 
¿Qué no puede interpretar ni entender? “[L]as vueltas del río [y] los posibles senderos en las selvas" aparecen como la sinécdoque de Cristy, pues ellos representan su mundo. Es decir, Leticia se siente extranjera en ese mundo de Cristy; no ha logrado descifrar las claves de su mundo; de ahí la extrañeza, el sentirse en un espacio que no es el propio. Siempre volviendo al comentario sobre la geografía, la frase siguiente es aún más significativa del estado de su ánimo, ¿cómo no interpretar también la pérdida del rumbo en el río al que se refiere Leticia en su sentido metafórico? Ella también se ha extraviado, ha perdido su rumbo y no encuentra una salida a su universo existencial. Más adelante se aclara esta equivalencia entre espacio natural y hombre, cuando Leticia se refiere a la selva como el lugar propio de Cristy, su circunstancia:

\footnotetext{
El amor la ha arrancado de sus paisajes de casas, volcanes, carreteras, campos de algodón; para vivir su propia historia de amor.

En donde nadie los aguarde, en el mundo de Cristy, cercano y lejano al de ella, separados ambos por una cortina de árboles y ríos (26).
}

Llama poderosamente la atención el verbo "arrancar"; implica que la separación ha sido violenta o abrupta, que no ha sido una decisión libre o meditada tal vez. La razón se halla en la frase siguiente; si bien es cierto alude a la orografía que separa el paisaje de ambas costas nicaragüenses, la distancia y el muro infranqueable, que se erigen, no son solo geográficos, sino también metafóricos al implicar la incomunicación de la pareja y las diferencias que son ahora insalvables. La comunión con la naturaleza es ahora imposible; Leticia siente la hostilidad y extrañeza ante esa selva que, al principio, mira con sorpresa y transtornada de encanto, intentando adaptándose a este lugar que le parece paradisíaco ${ }^{11}$. El embarazo y el niño recién nacido agudizan y acrecientan estas diferencias; se percata primeramente de que, como Eva en el Edén, se encuentra sola con su hijo en la inmensidad de la selva, lejos de una civilización que implica comodidades y seguridad; paulatinamente, madura la decisión inevitable ante esa soledad e incomunicación físicas, pero también espirituales:

\footnotetext{
En el fondo de su cerebro va naciendo día a día la idea de irse, de huir... De alejarse con el niño de esos parajes húmedos y sombríos.

Regresar a su mundo. Se sabe rodeada de agua y cree no tener el valor de planteárselo a Cristy, de llevarse sola al niño.

En su rostro, antes luminoso, no se refleja ya la luz. Rostro sombrío y callado (72).
}

No lo hace solamente por su hijo. Las relaciones de pareja se han deteriorado y la comunicación es imposible; la carencia de afecto es sintomática. Insiste Rosario Aguilar en la ausencia de un lenguaje corporal que haga dialogar a la pareja, en las miradas esquivas, en los silencios profundos, en la rutina del "matrimonio"12 que carcome ${ }^{13}$. Cristy sospecha y abiertamente se lo espeta en la cara: "El niño le pertenece a él, a sus selvas. Nadie le tocará ni se lo llevará lejos" (74). Leticia sabe que Cristy la perseguirá hasta el último confín del mundo. Temerosa en un primer momento transige, pero no aguanta más su situación ni quiere cumplir desde ahora su papel de esposa sumisa y pasiva a los designios del macho; se rebela: "Su cuerpo comenzó a negarse repentinamente al amor" (97). La liberación tiene un precio y empieza por la puesta en escena del principio autobiográfico; se trata de un examen de conciencia que la obliga a examinar el espacio de lo vivido con el fin de hacer un balance; contrasta así el desfase existente entre ese fuego ardoroso del principio del amor, en donde la naturaleza indómita comulga con la pareja y los acompaña en sus ritos amorosos casi salvajes ${ }^{14}$, y la situación 
presente. El idilio edénico es aparente, de manera que contrasta con la sensación de aprisionamiento, de desolación, de una selva que ahoga espiritualmente a Leticia. Comprendemos que Leticia, al contrario de lo que indica su onomástica, no es feliz en esos parajes. El desengaño amoroso surge como un eje estructurante que impide la realización personal y conduce al fracaso vital de lo que llama María Amoretti el ansia de transcendencia. Por ello, Leticia sabe que si se queda todo acabará mal; un sueño premonitorio en el que ella asesina a Cristy la obliga a tomar la fatal decisión:

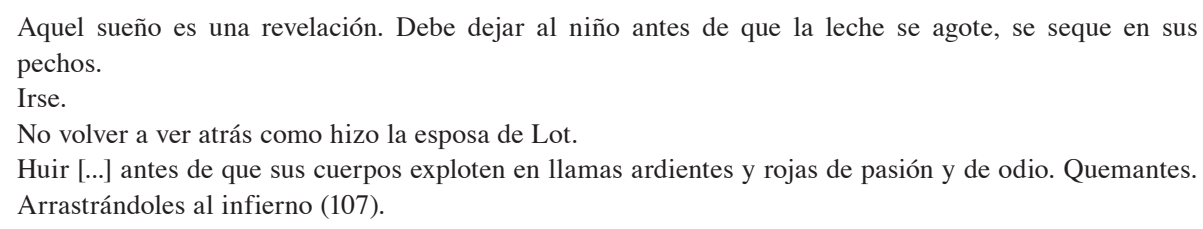

$\mathrm{Su}$ determinación significa hacer el sacrificio del hijo; una parte de ella queda en Sunnie Lagoon, con la maternidad frustrada e incompleta que se desarrolla en todas las historias de Siete relatos, salvo en la de Margarita Madariaga.

El desengaño amoroso y los problemas propios de maternidad son también los ejes estructurantes de la historia de Paula, la hermana de Leticia. Con Paula se narra el caso de la típica joven que, habiendo abrazado la causa de la guerrilla, ahora se dedica al trabajo administrativo propio de la burocracia. La reconstrucción del país requiere que los antiguos combatientes se dediquen a labores de oficina, que Paula hace con devoción, "pues daría su vida por la causa" (23), dice el texto, destacando su responsabilidad política y el amor con el que hace su trabajo en una oficina que hace trámites de reclamaciones de propiedades y de tierras confiscadas. Allí es donde conoce a Edy, el esposo de María Elena, a quien su familia en el exilio de Miami ha encargado el asunto de la devolución de su patrimonio. Desde el inicio, a Paula le llama la atención el joven buen mozo, atractivo, bien vestido y con gestos que delatan su origen burgués, pues Edy contrasta en un ambiente en el que, a Paula, los muebles y los compañeros de la oficina se ven burdos, sin distinción y armonía. En este contexto surge la contradicción entre su credo político y el concepto de matrimonio:

Quería si algún día se encontraba al hombre apropiado, casarse en ceremonia religiosa, con vestido blanco, velo y azahares... entregarse únicamente por amor, y que los hombres la respetaran (23-4).

El idealismo del matrimonio burgués debe interpretarse a la luz del melodrama que Rosario Aguilar empieza a montar entre Paula y Edy. Este último corteja y halaga a Paula con miras de que lo ayude con sus papeles y que su expediente llegue a la Procuraduría de la República. Frente al interés personal y a la utilización que hará Edy de su relación con Paula, se encuentra las ilusiones del amor perfecto que la joven muchacha se forja. Esto claramente se delimita desde la primera invitación para almorzar, cuando Paula justifica en forma de pregunta las razones para salir con Edy: “¿Por qué no podía ella aceptar una invitación a almorzar con un amigo del jefe, tan guapo y decente, que al parecer salía de una de las novelas de Corín Tellado?" (25). La comparación entre Edy y el típico protagonista de la novela rosa no es inocente; inconscientemente, Paula busca a su héroe y un amor de novela, un idilio con grandes emociones y una relación basada en sentimientos y pasiones de película romántica; las típicas 
ilusiones de un matrimonio con un galán surgen cuando las atenciones de Edy se vuelven insistentes, como cuando la trae o la lleva en su automóvil: "Se sentía como en una carroza, y él era para ella como el príncipe rubio y soñado" (46).

De manera que las aspiraciones de Paula no coinciden con los ideales revolucionarios ni con la construcción de una sociedad igualitaria; ella prefiere un valor que ataca el nuevo orden vigente, que se supone ella defiende. Se encuentra en una situación delicada, entre sus ideales de izquierda y la confrontación en la lucha de clases, por un lado, y la boda de blanco por otro: “...con velo, corona y azahares... la que criticaba tanto a la burguesía” (46). Los sentimientos de culpabilidad surgen después de que regresan de un perfecto fin de semana en Pochomil, con playa, paseos y atardeceres:

\footnotetext{
Lloró y sufrió un shock emocional, un arrepentimiento... no debía ser así, era como traicionar a los héroes y mártires de la revolución que tanto admiraba, con quienes luchó y sufrió (47).
}

La "autocrítica", como la denomina el narrador (47), se confunde con una serie de explicaciones, proporcionadas con el fin de exculparla; se exponen a continuación ciertos detalles de la vida de Paula que sirven para justificar, en gran parte, las razones por las cuales empieza a tomar a Edy como un verdadero pretendiente: una adolescencia y una juventud de "[s]acrificios y renunciamiento" (47), de carencialidades afectivas porque queda huérfana siendo adolescente o de entrega a una causa revolucionaria que nunca le dejó el tiempo para socializar. Ello hace más difícil la experiencia límite en la que se debate Paula, seguir los dictados de su corazón ahora que ha encontrado un hombre que parece quererla, o mantener incólume sus ideales anti-burgueses. Hay en Paula confusión, pero que Edy sabe despejar con sus regalos, galanterías y visitas, a medida en que ella va cediendo y se va aislando del mundo revolucionario. Por ejemplo, en la nueva oficina en la que trabaja, dependencia del Ministerio del Interior, sus compañeros (camaradas) de trabajo se apartan cuando se enteran de que sale con un "burgués"; agrega el narrador:

Tal vez era el precio que estaba pagando por enamorarse de un burgués y sus compañeros lo resentían.

Se alejaban de ella mientras iba cayendo, sin poder evitarlo, en aquel vértigo luminoso, delicioso, bello (67).

Paula cede por encima de sus ideales revolucionarios y se deja llevar por el idilio amoroso que culmina, muy lógico en este contexto, con el embarazo y nacimiento de una niña, la cual desde los primeros meses tiene una salud frágil. La novela de nuevo pone de manifiesto la ausencia del compañero en esos meses en los que Paula se arregla como puede. Cuando regresa a Nicaragua, Edy le pide perdón por el abandono y, aunque se ocupa económicamente de la niña, no demuestra verdadero cariño. A la niña le descubren una grave enfermedad de los riñones (84) y Paula se enfrenta a la dura prueba, a la situación límite de velar por una niña que necesita un tratamiento médico especial. La grave enfermedad de su hija hace que Paula aterrice en su dura y triste realidad: "Pero de golpe aterrizó en su mundo, en su realidad, en su posición. No soñaría más” (103). El idilio y su sueño romántico han terminado y ahora debe recurrir a su jefe para conseguirle a su hija un tratamiento médico en Cuba. De alguna manera, sobre Paula cae la sanción moral y un castigo; al alejarse de su compromiso revolucionario, al ceder a una relación sentimental con un burgués, Paula se ha equivocado. Dicho de otra manera, ha cometido un error que proviene de su mal juicio, 
porque, en contra de su ideario político, se ha abandonado a la búsqueda de una satisfacción amorosa imposible dentro de la tipología del relato sentimental (Chen 1999: 175).

Por lo tanto, las historias de mujeres, que nos presenta Siete relatos ${ }^{15}$, no tienen un desenlace completamente eufórico: plantean el desfase entre el proyecto de construcción nacional y las dificultades que, por ejemplo, Paula o Leticia encuentran para realizarse en un mundo machista. Hay mucho por hacer todavía para lograr el entendimiento y la igualdad entre hombres y mujeres. La revolución es también, como dice María Amoretti, de los sujetos He ahí el gran fracaso que Rosario Aguilar quiere testimoniar en Siete relatos; ello no se logra automáticamente con tomar las mismas armas codo a codo con los hombres, ni asumir juntos la reconstrucción del país. La revolución por hacer está en el plano de los afectos y de la comprensión de las diferencias biológicas y de género. Me parece que Aguilar no disimila ni oculta cuál ha sido la verdadera contradicción de la revolución sandinista en el ámbito de las subjetividades ${ }^{16}$; sus promesas en materia de género no llegan a materializarse del todo ${ }^{17}$ aunque su intento ha sido loable y merece nuestro respeto.

\section{Notas}

1. Este artículo surgió del seminario "El sujeto femenino en el relato de escritoras centroamericanas", que dicté en la Justus Liebig Universität-Giessen, durante enero y febrero del 2003. Agradezco al Servicio Alemán de Intercambio Académico (DAAD) la beca que me otorgó durante ese periodo, la cual hizo posible escribir este trabajo.

2. Ello excluiría a María Elena, en tanto personaje de extracción burguesa pero que no participa de la Revolución, pues huye a Miami. Además, por la importancia que recubre su historia en la Primera Parte de la novela, el tipo de desenlace que nos presenta (insatisfecha con su matrimonio, toma un amante y un empleo) y la importancia narrativa de su relato en primera persona, lo cual hablaría de su autonomía narrativa, impiden analizarla en este estudio.

3. Simplifico el título de la novela de ahora en adelante por razones obvias.

4. El artículo se publica en un número monográfico que dedica la Revista Iberoamericana a la literatura nicaragüense.

5. Al respecto comenta María de las Nieves Pinillos: "Básicamente, los puntos programáticos de las guerrillas vienen a ser:

- Luchar contra la miseria, la injusticia y la opresión.

- Buscar una organización social más justa; que no haya explotación del hombre por el hombre.

- Oponerse al imperialismo norteamericano" (176).

6. Valga la pena decir que no es la única, sino la tónica general en la novela.

7. Corrijo lo que me parece una errata del texto.

8. En el campo "se espera que su presencia en una zona actúe de catalizador de la colaboración popular. [...] También se realiza un rigur[o]so entrenamiento militar que sirve, entre otras cosas, para ejecutar emboscadas y mantener una labor de hostigamiento" (Pinillos 1983: 178). 
9. Coincidencias obligan, el tema de la maestra que esconde a un guerrillero se encuentra en una novela anterior de Aguilar El guerrillero (1976). Al respecto señala Nydia Palacios: "Rosario Aguilar, al escribir El guerrillero asumía un compromiso político al denunciar el horror de un país que vivía bajo la represión [de la dictadura]" (2000: 340).

10. Es curioso que esta decisión de Leticia de dejar su casa y su carrera se explique como una renuncia de parte de Leticia. Claro está, no es del mismo calibre que la renuncia que hace María José o Sonia en la Segunda Parte de la novela.

11. Por ejemplo, se podría ver esto como la iniciación de Leticia; véanse de las páginas 77 a la 81 de la novela. Al respecto, la escena final de ese capítulo responde perfectamente al tópico edénico con la fecundación/posesión de Leticia: “Quedaron embriagados de felicidad y, con las semanas, el vientre de la hembra comenzó a hincharse y él a sentir una ternura fiera y ancestral, posesiva” (81).

12. Ponemos matrimonio entre comillas porque, en ninguna parte de la novela, se dice abiertamente que estén casados.

13. No olvidemos que la estructuración del relato va contrastando y complementando las historias de Leticia, su hermana Paula y la de María Elena. Justamente en el capítulo siguiente, el XII, María Elena nos relata el fracaso de su matrimonio y el deterioro de las relaciones de pareja: "Cuando nuestro amor comenzó a enfriarse, aunque todavía nos queríamos y nos hacíamos el amor, era cada vez más obvio que su mente, su corazón, estaban lejos. [...] Hasta entonces mi vida la había llenado él. Cuando me dejaba sola me quedaba vacía" (75). ¡Qué coincidencias!

14. Por ejemplo: "Sintió un éxtasis. Un deseo de abrirse gozosa y generosa al ímpetu de aquella naturaleza y de aquel ser de quien ya nunca, jamás, se volvería a separar... Remarían eternamente por aquellos ríos. Vivirían felices. Se instalarían más al Oeste de Sunnie Lagoon, y verían el sol transformar cada día en mil matices... sí, serían felices para siempre" (99).

15. Salvo en el caso de María Elena; la única que, rompiendo con Nicaragua, rehace su vida privada y profesionalmente.

16. Claro está, ello deriva no tanto de lo que dice, sino de lo que debemos inferir en la novela. No hace un simple panfleto político.

17. Opinión que asume Pilar Moyano en un penetrante artículo que revisa esto mismo en la poesía de Gioconda Belli (321).

\section{Bibliografía}

Aguilar, Rosario. 1986. Siete relatos sobre el amor y la guerra. San José: EDUCA.

Amoretti, María. 1997. "La morada interior y sus espectros". En Arancibia, Juana A. y Luis Jiménez (Eds.), 275-300.

Arancibia, Juana A. y Luis Jiménez (Eds.). 1997. Protestas, Interrogantes y Agonías en la obra de Rima de Vallbona. San José: Instituto Literario y Cultural Hispánico-Ediciones de Perro Azul. 
Chen Sham, Jorge. 1999. "Sanción moral y castigo: contradicciones ideológicas en la narrativa de Ana Roqué”. En Jiménez, Luis A. (Comp.), 167-80.

2002. "Tres momentos de los movimientos revolucionarios vistos en la literatura latinoamericana: Benedetti, Argueta y Vargas Llosa". Revista de Filología y Lingüística de la Universidad de Costa Rica. 28 (2): 51-62.

Jiménez, Luis A. (Comp.). 1999. La voz de la mujer en la literatura hispanoamericana fin-desiglo. San José: Editorial de la Universidad de Costa Rica.

Moyano, Pilar. 1993. "La transformación de la mujer y la nación en la poesía comprometida de Gioconda Belli”. Revista Canadiense de Estudios Hispánicos. 17 (2): 319-31.

Palacios, Nydia. 1998. Voces femeninas en la narrativa de Rosario Aguilar. Managua: Editorial Ciencias Sociales.

2002. "El guerrillero de Rosario Aguilar: la mujer en la Revolución Nicaragüense en la década de los sesenta". Alba de América. 19 (35-36): 339-45.

Pinillos, María de las Nieves. 1983. "La novela de la guerrilla iberoamericana”. Cuadernos Hispanoamericanos. (400): 174-82.

Rubio Cordón, José Luis. 1983. “Los movimientos vertebradores, populistas y revolucionarios en Iberoamérica”. Cuadernos Hispanoamericanos. (398): 343-57.

Salamanca, Douglas. 1991. "Literatura, sandinismo y compromiso". Revista Iberoamericana. (157): 843-59.

Zamora, Daisy. 1991. "La mujer nicaragüense en la poesía”. Revista Iberoamericana. (157): 933-58. 